for the treatment of schizophrenia, delusions and manic bipolar disorder [19]. No cases of pleural disease following treatment with olanzapine have been reported so far in the literature. However, several cases of pulmonary adverse events have been described following treatment with clozapine, including subacute diffuse interstitial pneumonitis and exudate pleural effusions, occasionally eosinophilic [20-23]. We have not found a study that could elucidate the immunological mechanisms of these reactions.

In conclusion, eosinophilic pleural effusion is an uncommon disease in which aetiologies are difficult to establish. We must remember that the eosinophilic pleural effusion is not always benign and may be malignant. Drug-induced eosinophilic pleural effusion is a potential aetiology to search and should be considered as it can be treated easily.

\section{K. Alagha, C. Tummino, T. Sofalvi and P. Chanez}

Activités ambulatoires du pôle thorax et clinique des bronches, de l'allergie et du sommeil, AP-HM, Laboratoire d'Immunologie INSERM CNRS U 600, UMR6212, Université de la Méditerranée, Marseille, France.

Correspondence: K. Alagha, AP-HM, Hôpital Nord, Chemin de Bourelly, 13015 Marseille, France. E-mail: khuder.alagha@ ap-hm.fr

Statement of Interest: P. Chanez has provided consultancy services for Almirall, Boehringer Ingelheim, Centocor, GlaxoSmithKline, AstraZeneca, Novartis, Teva, Chiesi and Schering Plough; served on advisory boards for Almirall, Boehringer Ingelheim, Centocor, GlaxoSmithKline, AstraZeneca, Novartis, Teva, Chiesi and Schering Plough; received lecture fees from Almirall, Boehringer Ingelheim, Centocor, GlaxoSmithKline, AstraZeneca, Novartis, Teva, Chiesi and Schering Plough; and received industry-sponsored grants from Almirall, Boehringer Ingelheim, Centocor, GlaxoSmithKline, AstraZeneca, Novartis, Teva, Chiesi and Schering Plough.

Provenance: Submitted article, peer reviewed.

\section{REFERENCES}

1 Petusevsky ML, Faling LJ, Rocklin RE, et al. Pleuropericardial reaction to treatment with dantrolene. JAMA 1979; 242: 2772-2774.

2 Dohen F, Montagne V, Lelieur E. Pleurésie médicamenteuse au dantrolène: á propos d'un cas [Dantrolene-induced pleurisy: a case report]. Rev Pneumol Clin 2000; 56: 261-263.

3 Miller DH, Haas LF. Pneumonitis, pleural effusion and pericarditis following treatment with dantrolene. J Neural Neurosurg Psychiatry 1984; 47: 553-554.
4 Felz MW, Haviland-Foley DJ. Eosinophilic pleural effusion due to dantrolene: resolution with steroid therapy. South Med J 200l, 94: 502-504.

5 Bhatti MA, Zander J, Reeve E. Clozapine-induced pericarditis, pericardial tamponade, polyserositis, and rash. J Clin Psychiatry 2005; 66: 1490-1491.

6 Huggins JT, Sahn SA. Drug-induced pleural disease. Clin Chest Med 2004; 25: 141-153.

7 Boot E, de Haan L, Guzelcan Y, et al. Pericardial and bilateral pleural effusion associated with clozapine treatment. Eur Psychiatry 2004; 19: 65.

8 Light RW, ed. Pleural Diseases. 3rd ed. Baltimore, Williams and Wilkins, 1995.

9 Adelman M, Albelda SM, Gottlieb J, et al. Diagnostic utility of pleural fluid eosinophilia. Am J Med 1984; 77: 915-920.

10 Wysenbeek AJ, Lahav M, Aelion JA, et al. Eosinophilic pleural effusion: a review of 36 cases. Respiration 1985; 48: 73-76.

11 Martinez-Garcia MA, Cases-Viedma E, Cordero-Rodriguez PJ, et al. Diagnostic utility of eosinophils in the pleural fluid. Eur Respir I 2000; 15: 166-169.

12 Mahoney JM, Bachtel MD. Pleural effusion associated with chronic dantrolene administration. Ann Pharmacother 1994; 28: 587-589.

13 Lê-Quang B, Calmels P, Valayer-Chaléat E, et al. Dantrolene and pleural effusion: case report and review of literature. Spinal Cord 2004; 42: 317-320.

14 Faling LJ, Petusevsky ML, Snider GL. Nitrofurantoin and dantrolene: liver and lung. Ann Intern Med 1980; 93: 151.

15 Israel HL, Diamond P. Recurent pulmonary infiltration and pleural effusion due to nitrofurantoin sensitivity. $N$ Engl J Med 1962; 266: 1024-1026.

16 Rosenow EC, De Remee RA, Dines DE. Chronic nitrofurantoin pulmonary reaction. Report of five cases. N Engl J Med 1968; 279: $1258-1262$.

17 Holmberg L, Boman G. Pulmonary reactions to nitrofurantoin: 447 cases reported to the Swedish Adverse Drug Reaction Committee 1966-1976. Eur J Respir Dis 1981; 62: 180-189.

18 Benard A, Guenanen H, Tillie-Leblond I, et al. Pleurersies médicamenteuses [Drug induced pleurisy]. Rev Mal Resp 1996; 13: 227-234.

19 Association mieux prescrire. Effets indésirables métaboliques de l'olanzapine: procès en cascade aux Etats-Unis [Adverse metabolic effects of olanzapine: cascading trial in the US]. Rev Prescrire 2008; 28: 224-226.

20 Pan R, John V, Hagg S. Clozapine and pulmonary embolism. Acta Psychiatrica Scandinavica 2003; 108: 76-77.

21 Stanislav SW, Gonzalez-Blanco M. Papular rash and bilateral pleural effusion, associated with clozapine. Ann Pharmacother 1999; 33: 1008-1009.

22 Benning TB. Clozapine-induced extrinsic allergic alveolitis. $\mathrm{Br} \mathrm{J}$ Psychiatry 1998; 173: 440-441.

23 Chatterjee A, Safferman AZ. Cellulitis, eosinophilia, and unilateral pleural effusion associated with clozapine treatment. J Clin Psychopharmacol 1997; 17: 232-233.

DOI: $10.1183 / 09059180.00000211$

\title{
Blind needle biopsy of the pleura: why not?
}

\section{To the Editor:}

We read with great interest the excellent review by JANSSEN [1] in the September issue of the European Respiratory Review, where the author highlights the position of thoracoscopy in the current diagnostic armamentarium of pneumonology and nicely concentrates the up-to-date knowledge in the field. 
As a general comment, we would say that thoracoscopy is not a panacea for the diagnosis of pleural effusions; however, the value of blind needle biopsy of the pleura (or closed-pleural biopsy; CPB) may not actually be so limited.

Thoracoscopy is essentially the best way to biopsy the pleura. However, not all diseases that affect the pleura can be diagnosed by pleural biopsy, even with the best techniques. The main histological abnormalities of the pleura that demonstrate disease specificity are those associated with malignant and granulomatous disorders, the most frequent representative of the latter disease category being tuberculosis (TB) $[2,3]$. Thus, pleural biopsy (and thoracoscopy) can virtually diagnose two main disorders: malignant pleural effusions (MPEs) and TB pleuritis. In the case that the patient does not suffer from either of them, the pathologist will most probably diagnose "nonspecific pleuritis". Although "not specific", this diagnosis can exclude malignancy because of the high negative predictive value of thoracoscopy for MPEs [4]. This observation highlights another important indication of thoracoscopy, which is the exclusion of malignancy (as well as TB).

In the aforementioned review, comparing the performance of the three main nonsurgical methods of pleural biopsy for the diagnosis of MPEs (table 1 in the review by Janssen [1]), i.e. $\mathrm{CPB}$, thoracoscopy and image-guided pleural biopsy (under computed tomography or ultrasound guidance), the inferiority of CPB for this specific purpose is demonstrated (sensitivity $45 \%$ ). However, for the diagnosis of the other main disorder that can be diagnosed by pleural biopsy, namely TB pleuritis, the performance of both $\mathrm{CPB}$ and thoracoscopy is much better (sensitivity $79 \%$ and $100 \%$ respectively) [5], while to the best of our knowledge there are no available data for image-guided pleural biopsy. Based on the information depicted in this table, the author concludes that CPB "should no longer be used in a setting where image-guided pleural biopsies can be obtained" and that $\mathrm{CPB}$ "is only indicated in areas with high incidence of TB and limited medical resources". Although this conclusion might reflect the general opinion regarding $\mathrm{CPB}$, we do not totally agree with this position.

First of all, for the diagnosis of MPEs it is unknown if the suggestion for the usage of image-guided pleural biopsy instead of $\mathrm{CPB}$, which is mainly based on the results of the study by MASKELL et al. [6], can be equally applied in less experienced and/or less specialised centres in the field. Before advising pneumonologists to stop performing $\mathrm{CPB}$, we should probably consider whether all radiologists are trained to obtain image-guided pleural biopsies and if they will be available when we need them.

Regarding thoracoscopy, not all patients with an MPE are appropriate candidates for this method. Poor performance status, severe dyspnoea or significant pain due to bone metastases, that does not allow the patient to obtain the typical body position for thoracoscopy, might be indications for a more conservative approach. The alternative of $\mathrm{CPB}$ might then be offered if tissue information is considered necessary for the patient's further work-up. For these individual cases, a diagnostic sensitivity of $45 \%$ for $\mathrm{CPB}$, although "low" compared to 95\% for thoracoscopy, might still be a reasonable option. If $45 \%$ of patients with MPE are expected to gain some benefit from this technique then, why not try?

In comparison to thoracoscopy, $\mathrm{CPB}$ is much less invasive, less painful and perhaps more tolerable from the patient's perspective. In fact, $\mathrm{CPB}$ is not very different from a simple thoracocentesis regarding the technique itself, as well as the overall complications. Its great advantage of simplicity and negligible complication rate may save time and effort for the medical staff and discomfort for patients. These benefits are unequivocally important, especially in patients who suffer from malignancy and have a limited life expectancy. Obviously, CPB should not be considered as an equal alternative of thoracoscopy. However, it could be performed as a complementary technique in the context of diagnostic or therapeutic thoracocentesis. Indeed, some of these interventions, at times, may precede the decision for thoracoscopy, as it is important to evaluate the rate of recurrence of the pleural fluid or if lung re-expansion is possible.

In the case of $\mathrm{TB}$ pleuritis the option of $\mathrm{CPB}$ might be even stronger because of its high diagnostic sensitivity, which in some studies approximates that of thoracoscopy [7]. In view of these data, one might choose to perform CPB before proceeding to thoracoscopy in a case suspicious for $\mathrm{TB}$, and this approach might be acceptable in both high- and low-incident areas. In our clinic we have performed thoracoscopy for the past 6 yrs, with the main indication being that of undiagnosed pleural effusions. Unfortunately, we have not had the opportunity to thoracoscopically diagnose a TB pleutiris, as the few patients we had were diagnosed by CPB. And we do not believe we did wrong. However, it should always be stressed that even for $\mathrm{TB}$, in case of a nondiagnostic $\mathrm{CPB}$, the best answer remains thoracoscopy.

In addition to all the aforementioned issues, there are two more different but equally important parameters. The first is that of the patient's preferences. If the patient does not wish to be involved in thoracoscopy then other options should be available, including blind needle biopsy. The second has to do with the training of chest physicians. If tertiary hospitals, which are usually responsible for the training of the new specialists in pulmonary medicine, choose to eliminate $\mathrm{CPB}$ from their diagnostic tools, then the newer generations of pneumonologists will not be familiar with this technique at all. This means that in the near future the pneumonologists who are going to staff hospitals "with limited resources" will actually not be able to perform pleural biopsies. In that case, will the surgeons diagnose TB for us or should we proceed into patients' transfers between hospitals to obtain a small piece of tissue?

In conclusion, we believe that sensitivity alone might not be the only criterion for a physician to opt for a diagnostic test. Pneumonologists should ideally master the full spectrum of the available diagnostic methods in their field and then choose the most feasible option for their patients on a case by case basis.

\section{K. Psathakis and V. Skouras}

Dept of Pneumonology, Army General Hospital of Athens, Athens, Greece. 
Correspondence: K. Psathakis, Terpsichoris 61, 17341 Agios Dimitrios, Athens, Greece. E-mail: kpsazakis@hol.gr

Statement of Interest: None declared.

Provenance: Submitted article, peer reviewed.

\section{REFERENCES}

1 Janssen JP. Why you do or do not need thoracoscopy. Eur Respir Rev 2010; 19: 213-216.

2 Cagle PT. Pleural histology. In: Light RW, Lee YCG, eds. Textbook of Pleural Diseases. London, Hodder Arnold, 2003; pp. 249-255.

3 Rodriguez-Panadero F, Janssen JP, Astoul P. Thoracoscopy: general overview and place in the diagnosis and management of pleural effusion. Eur Respir J 2006; 28: 409-421.

4 Janssen JP, Ramlal S, Mravunac M. The long-term follow-up of exudative pleural effusion after nondiagnostic thoracoscopy. J Bronchol 2004; 11: 169-174.

5 Diacon AH, Van de Wal BW, Wyser C, et al. Diagnostic tools in tuberculous pleurisy: a direct comperative study. Eur Respir J 2003; 22: 589-591.

6 Maskell NA, Gleeson FV, Davies RJ. Standard pleural biopsy versus CT-guided cutting-needle biopsy for diagnosis of malignant disease in pleural effusions: a randomised controlled trial. Lancet 2003; 361: 1326-1330.

7 Gopi A, Madhavan SM, Sharma SK, et al. Diagnosis and treatment of tuberculous pleural effusion in 2006. Chest 2007; 131: 880-889.
From the author:

I thank K. Psathakis and V. Skouras for their detailed comments. Although it has been demonstrated that the additional diagnostic yield of blind-pleural biopsy in the diagnosis of malignant pleural effusion to thoracocenthesis is limited to $7 \%$, some pulmonary physicians persist in using this technique, also in countries with low prevalence of tuberculosis.

In my article, I stated that "Closed pleural biopsy should no longer be used in a setting where image-guided pleural biopsies can be obtained." In my opinion, this statement is true for modern medicine in general. An image-guided technique, if available, is preferred over a blind procedure to obtain tissue for a histological diagnosis.

If in a situation that is getting rare in Europe and throughout the western world, thoracoscopy or image-guided biopsy facilities (computed tomography or ultrasound) are not available, closed pleural biopsy may be performed to obtain a diagnosis. Because of the poor results of this technique, and the general availability of three better options, closed pleural biopsy has been eliminated from the training programme of chest physicians in my hospital.

\section{J. Janssen}

Correspondence: J. Janssen, Canisius Wilhelmina Hospital, Post Box 9015, 6500 GS Nijmegen, The Netherlands. E-mail: j.janssen@cwz.nl

Statement of Interest: None declared.

Provenance: Submitted article, peer reviewed. 